Article

\title{
High-Voltage Sulfolane Plasticized UV-Curable Gel Polymer Electrolyte
}

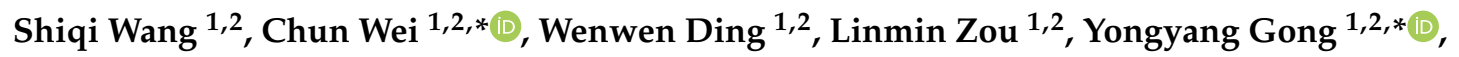 \\ Yuanli Liu 1,2, Limin Zang ${ }^{1,2}$ and $\mathrm{Xu} \mathrm{Xu}{ }^{1,2}$ \\ 1 College of Materials Science and Engineering, Guilin University of Technology, Guilin 541004, China \\ 2 Key Laboratory of New Processing Technology for Nonferrous Metals and Materials, Ministry of Education, \\ Guilin 541004, China \\ * Correspondence: 1986024@glut.edu.cn (C.W.); yygong@glut.edu.cn (Y.G.)
}

Received: 30 June 2019; Accepted: 2 August 2019; Published: 4 August 2019

\begin{abstract}
A high-voltage electrolyte can match high-voltage positive electrode material to fully exert its capacity. In this research, a sulfolane plasticized polymer electrolyte was prepared by in situ photocuring. First, the effect of the sulfolane content on the ionic conductivity of the gel polymer electrolyte was investigated. Results showed that the ionic conductivity variation trend was in good agreement with the exponential function model for curve fitting. Second, the activation energy was calculated from the results of the variable temperature conductivity tests. The activation energy was inversely proportional to the sulfolane content. For the sulfolane content of $80 \mathrm{wt}$. \% in gel polymer electrolyte (GPE)-80 (19.5 kJ/mol), the activation energy was close to conventional liquid electrolyte $(9.5 \mathrm{~kJ} / \mathrm{mol})$, and the conductivity and electrochemical window were $0.64 \mathrm{mS} / \mathrm{cm}$ and $5.86 \mathrm{~V}$, respectively. The battery cycle performance test showed that the initial specific discharge capacities of GPE-80 and liquid electrolyte were 176.8 and $148.3 \mathrm{mAh} / \mathrm{g}$, respectively. After 80 cycles, the discharge capacities of GPE-80 and liquid electrolyte were 115.8 and $41.1 \mathrm{mAh} / \mathrm{g}$, and the capacity retention rates were $65.5 \%$ and $27.7 \%$, respectively; indicating that GPE- 80 has a better specific discharge capacity and cycling performance than the liquid electrolyte. SEM images indicated that GPE- 80 can suppress the growth of lithium dendrites. The EDS test showed that GPE-80 can inhibit the dissolution of metal ions in the cathode material.
\end{abstract}

Keywords: lithium battery; sulfolane; gel polymer electrolyte; high-voltage electrolyte; UV curable

\section{Introduction}

The lithium-ion batteries are being widely used, because of the growing requirement for mobile phones, electric vehicles and drones [1-3]. However, the traditional lithium-ion battery has a low capacity and cannot meet long-life application demands. Therefore, there is an urgent need to develop a battery with a higher specific capacity [4]. Generally, to greatly increase the specific capacity of a battery, it is necessary to develop positive and negative materials. For example, synthetic, higher capacity positive and negative materials increase the use voltage of the positive electrode material, and the use of lithium metal or silicon negative electrodes.

The NCM (Ni-rich transition metal oxide) cathode material has a high specific capacity $(>200 \mathrm{mAh} / \mathrm{g})$ and is typically used at a voltage of $4.3 \mathrm{~V}[5,6]$. Further increasing the use voltage of this positive electrode material can increase its energy density and power density. However, a conventional liquid electrolyte has a low electrochemical window, usually less than $4.5 \mathrm{~V}$ [7]. Therefore, it is necessary to develop a higher voltage electrolyte to match the cathode material.

Conventional liquid electrolytes have high conductivity and low cost, but their low boiling point, volatility, flammability and explosivity are fatal defects $[8,9]$. Therefore, it is desirable to develop a 
high boiling point, highly stability electrolyte material to replace them. Solid and gel electrolytes have become the main research directions [10,11]. However, the presence of a solid electrolyte with low conductivity makes it difficult for operations at room temperature, and the electrolyte and the active material have poor interfacial contact [11]. A gel polymer electrolyte (GPE) has a conductivity comparable to that of a liquid electrolyte and has safety features similar to those of a solid electrolyte, making gel electrolytes the preferred choice for current battery manufacturers [12].

Researchers have conducted research on high-voltage gel electrolytes $[9,13]$. Succinonitrile has a high oxidation potential and has been extensively studied [14-16]. Lin et al. studied a succinonitrile plasticized PEGDA (Poly(ethylene glycol) diacrylate) photopolymer gel electrolyte, which is a gel electrolyte with a modulus of $0.43 \mathrm{GPa}$ and an ionic conductivity of $0.6 \mathrm{mS} / \mathrm{cm}\left(30^{\circ} \mathrm{C}\right)$ after in situ photocuring [17]. Lv et al. prepared succinonitrile plasticized polyurethane acrylate (PUA) with a conductivity of $1.63 \times 10^{-3} \mathrm{~S} / \mathrm{cm}$ and an oxidation potential reaching $5.3 \mathrm{~V}$ using a photopolymer gel electrolyte [18]. Li et al researched a dual-salt LiTFSI/LiBOB polymer electrolyte plasticized by glutaronitrile [19]. The ionic conductivity of the polymer electrolyte reached over $1.0 \mathrm{mS} / \mathrm{cm}\left(30^{\circ} \mathrm{C}\right)$, and the oxidation potential was above $5 \mathrm{~V}$.

Sulfolane is a well-known high-voltage electrolyte additive with a high dielectric constant (43.4) and high oxidation potential $(>6.35 \mathrm{~V})$ [20]. Cui et al. researched and used this electrolyte with a high-voltage cathode material $\mathrm{LiNi}_{0.5} \mathrm{Mn}_{1.5} \mathrm{O}_{4}(4.7 \mathrm{~V})$ and achieved excellent cycling performance [20]. The oxidation potential of the sulfolane-based electrolyte was above $5.5 \mathrm{~V}$. Li et al. prepared a $\mathrm{LiBOB} /$ sulfolane/diethyl carbonate electrolyte that showed an excellent oxidation potential $(>5.3 \mathrm{~V})$ and high conductivity. The above studies show that sulfolane is a good high-voltage electrolyte material [21].

However, to the best of our knowledge, the use of sulfolane for in situ curing of plasticized polymer electrolytes has not been reported. Additionally, the conductivity and electrochemical window of sulfolane on polymers requires further research.

\section{Materials and Methods}

\subsection{Materials}

PEGDA600 $\left(M_{\mathrm{w}}=600\right)$, LiDFOB (lithium difluoro (oxalate) borate), Sulfolane, and NMP (1-methyl-2-pyrrolidone) were analytically pure and purchased from Shanghai Aladdin Biochemical Technology Co., Ltd. (Shanghai, China). Irgacure 819; NCM811 ( $\mathrm{Li}\left[\mathrm{Ni}_{0.8} \mathrm{Co}_{0.1} \mathrm{Mn}_{0.1}\right] \mathrm{O}_{2}$ cathode material), carbon black and PVDF were purchased from Xinghua Bennot Battery Material Co., Ltd. (Jiangsu, China). A $100 \mu \mathrm{m}$ thick FEP (fluorinated ethylene propylene) film was purchased from Suzhou Zeyou Fluorine Plastic Material Technology Co., Ltd. (Suzhou, China). A UV lamp (365 nm LED, 30 W) was purchased from Zhongshan Yanxizhao Lighting Electric Appliance Factory (Zhongshan, China).

\subsection{Methods}

\section{Preparation of GPE}

In a typical fabrication process for the preparation of an GPE film, PEGDA600, LiDFOB, sulfolane, and Irgacure 819 were mixed, added to a brown bottle, and stirred for $6 \mathrm{~h}$ to dissolve. A $100 \mu \mathrm{m}$ transparent FEP film was placed on a flat glass plate, and a PET film with a thickness of $90 \mu \mathrm{m}$ and a hole diameter of $18 \mathrm{~mm}$ was placed on top. Then, 2 drops of an electrolytic solution were dropped into the hole, covered with a $100 \mu \mathrm{m}$ FEP film, and pressed with a flat glass plate to extrude excess electrolyte. Curing was then carried out by irradiating the sample with a $365 \mathrm{~nm}$ UV lamp for $10 \mathrm{~min}$. The GPE film was obtained by peeling off the film from the mold.

The sulfolane content was controlled to be $0,20,40,60$, and $80 \mathrm{wt}$. \%, and the concentration of LiDFOB was fixed at 10.7 wt. \% (1.02 mol/L). Different GPEs were obtained, which were named GPE-0, GPE-20, GPE-40, GPE-60, and GPE-80, respectively. 
NCM811 and carbon black were mixed, added to the NMP-dissolved in PVDF, to form a solution with a solid content of $45 \mathrm{wt}$. \%, and stirred for $5 \mathrm{~h}$ to achieve uniform mixture (NCM811:C65:PVDF = 95:4:1). Then, the samples were coated on aluminum foil and dried in a $80^{\circ} \mathrm{C}$ vacuum oven for $24 \mathrm{~h}$ to obtain a positive electrode sheet.

The electrolyte was dropped onto a $16 \mathrm{~mm}$ diameter NCM811 electrode sheet, covered with a GPE film with a diameter of $18 \mathrm{~mm}$, and allowed to sit in the dark for $10 \mathrm{~min}$. Then, the samples were subjected to UV light and cured for $10 \mathrm{~min}$. A $16 \mathrm{~mm}$ lithium piece was placed and packaged in the battery case of a CR2025. The battery preparation process is shown in Figure 1.

A $1.1 \mathrm{~mol} / \mathrm{L}$ nonaqueous solution of LiPF6 (EC:DMC:FEC = 47.5:47.5:5) electrolyte was used for comparison as the liquid electrolyte.

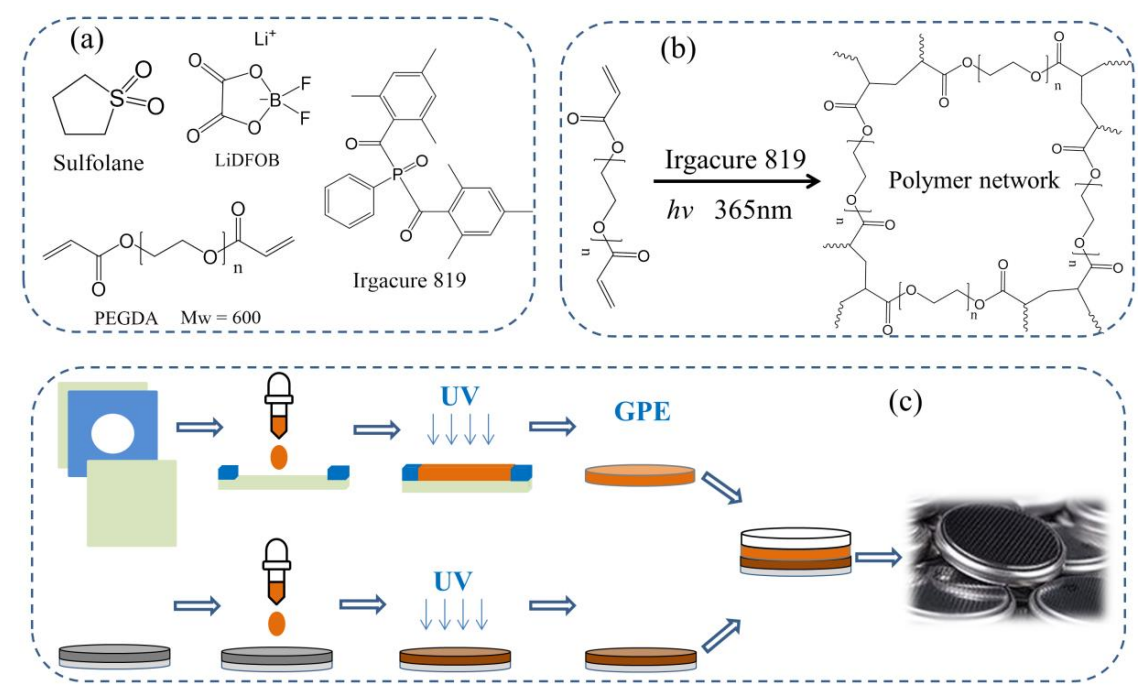

Figure 1. (a) Chemical structure of major chemicals; (b) Reaction mechanism and possible gel structure of the gel polymer electrolyte (GPE); (c) Flow chart of preparation of UV curing a GPE battery.

\subsection{Characterizations}

Fourier transform infrared spectroscopy (FTIR): The powder sample was ground with $\mathrm{KBr}$ and then pressed into a thin wafer for testing. Liquid samples were dropped onto a transparent $\mathrm{KBr}$ sheet for testing. Test was carried out on a NICOLETNEXUS470-type spectrometer (Perkin-Elmer Company, Waltham, MA, USA). The wavelengths were in the range of $4000-400 \mathrm{~cm}^{-1}$, and the resolution was $4 \mathrm{~cm}^{-1}$.

Field emission scanning electron microscopy (SEM) images: The sample was placed directly on the S-4800-type instrument (HITACHI Company, Tokyo, Japan) for testing (Acceleration voltage $5.0 \mathrm{kV}$ ). In the glove box, the sample was cut and adhered on the copper column with conductive adhesive. Then, it was sealed with a PE bag and quickly transferred to a test chamber of the SEM for testing. In order to prevent the oxidation of the lithium sheet happen.

Energy dispersive spectroscopy (EDS): The test was performed using an X-max type EDS instrument (HORIBA Company, Kyoto, Japan) mounted on an S-4800 SEM. Preparation method of samples were consistent with the SEM test.

Typically, electrochemical characterization was conducted with a CHI660E type electrochemical workstation (CH Instruments, Shanghai, China) at $30{ }^{\circ} \mathrm{C}$.

Ionic conductivity: Electrochemical impedance spectroscopy (EIS) measurements were used to calculate the conductivity of GPEs. The frequency was set to $1 \mathrm{~Hz}-100 \mathrm{kHz}$ with an amplitude of $5 \mathrm{mV}$. The sample was prepared as a stainless steel/GPE/stainless steel sandwich configuration for testing. The ionic conductivity $(\sigma)$ was be calculated by the Equation (1): 


$$
\sigma=\frac{\mathrm{d}}{\mathrm{R}_{b} \times \mathrm{S}}
$$

where $d$ and $S$ are the thickness and the effective area of the GPE, respectively, and $R_{b}$ is the bulk impedance of the electrolyte film [19]. Fitting the impedance spectroscopy obtains the intersection of the straight line and the $Z^{\prime}$ axis, which is the value of $R_{b}$. The impedance spectrum test data can be found in the supporting information (in Figure S1, Supplementary Materials). The ionic conductivity at different temperatures was tested by change the temperature from 30 to $90{ }^{\circ} \mathrm{C}$; the sample was kept in the incubator for at least $30 \mathrm{~min}$ before testing, and results are shown in Figure S2 (Supplementary Materials).

Electrochemical window test: Measurements were carried out using the SS|GPE|Li type cell configuration at $30^{\circ} \mathrm{C}$. The potential range was from -0.5 to $8.0 \mathrm{~V}$ with a sweeping rate of $2 \mathrm{mV} / \mathrm{s}$. Cycle performance of battery: The charge/discharge cycle stability test was performed using a BST-4800 type eight-channel battery analyzer ( $5 \mathrm{~V}, 50 \mathrm{~mA}$; NEWARE, Shenzhen, China) with a potential window of 2.75-4.3 V (versus $\mathrm{Li} / \mathrm{Li}^{+}$). The long cycle current density was set to $0.1 \mathrm{C}$ (with respect to the capacity of NCM811 of $180 \mathrm{mAh} / \mathrm{g}$ ). The rate performance test was carried out through different charge/discharge current densities, and the maximum specific capacity given by the manufacturer is $180 \mathrm{mAh} / \mathrm{g}$.

\section{Results and Discussion}

\subsection{Detecting of UV-Cured GPE}

In order to detect the successful photopolymerization from the chemical structure, we performed an FTIR test, and the results are shown in Figure 2. As shown in Figure 2a, the absorption peak at $1732 \mathrm{~cm}^{-1}$ is the $\mathrm{C}=\mathrm{O}$ stretching absorption of the acetate group of PEGDA [22,23]. The absorption peaks at 1634 and $810 \mathrm{~cm}^{-1}$ are vibration and the twisting vibration absorptions of the $C=C$ stretching of the acrylate groups, respectively $[23,24]$. Comparison of Figure $2 b, c$ shows that the characteristic peak of the $\mathrm{C}=\mathrm{C}$ double bond disappears after photopolymerization. This indicates successful and complete photopolymerization.
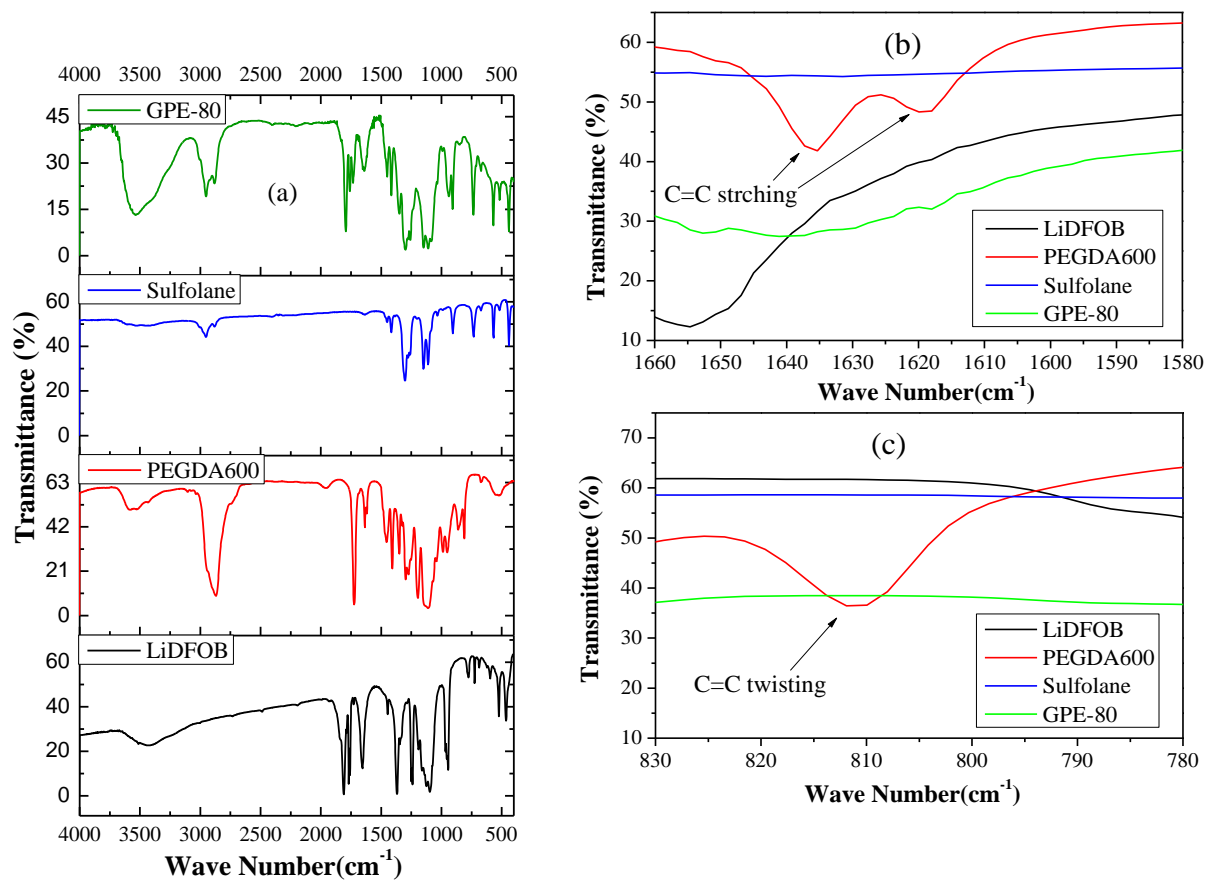

Figure 2. (a) FTIR results of raw materials and GPE-80, (b) Enlargement of $1660-1580 \mathrm{~cm}^{-1}$. (c) Amplification of $830-780 \mathrm{~cm}^{-1}$. 


\subsection{Effect of Sulfolane Content on GPE}

In order to research the effect of sulfolane content on the ionic conductivity, we fixed the lithium salt content at $10.7 \mathrm{wt}$. $\%(1.02 \mathrm{~mol} / \mathrm{L})$. GPEs containing 0 to $90 \mathrm{wt}$. \% of sulfolane were prepared. Their conductivity was tested at $30^{\circ} \mathrm{C}$ (in Figure S1, Supplementary Materials). The scatter plot of the content of sulfolane and the ionic conductivity of the corresponding GPEs were obtained, and are shown in Figure 3a. Through the curve fitting, we found that the variation trend was in good agreement with the exponential function model, and the fitting result is shown in Figure 3a. The $\mathrm{R}^{2}$ of the fitting result reached 0.9959 , indicating that it has a good correlation. The change trend is represented by the function in Equation (2).

$$
\sigma=\exp \left(-10.989+21.48 c-10.44 c^{2}\right)
$$

where $\sigma$ is the ionic conductivity of the GPE at $30{ }^{\circ} \mathrm{C}$, in $\mathrm{mS} / \mathrm{cm}$. $c$ is the content of sulfolane, in wt. \%. Clearly, the ionic conductivity of GPE increases faster when the sulfolane content is higher than $50 \%$. The results show that when the content of sulfolane is 70,80 , and $90 \mathrm{wt}$. \%, the ionic conductivity of the gel electrolyte reaches $0.31,0.64$, and $0.89 \mathrm{mS} / \mathrm{cm}$, respectively. However, when the sulfolane content is $90 \mathrm{wt} . \%$, the strength of the gel electrolyte is too low to be handled. Therefore, we chose GPE-80, with a sulfolane content of $80 \mathrm{wt}$. \% for additional studies.
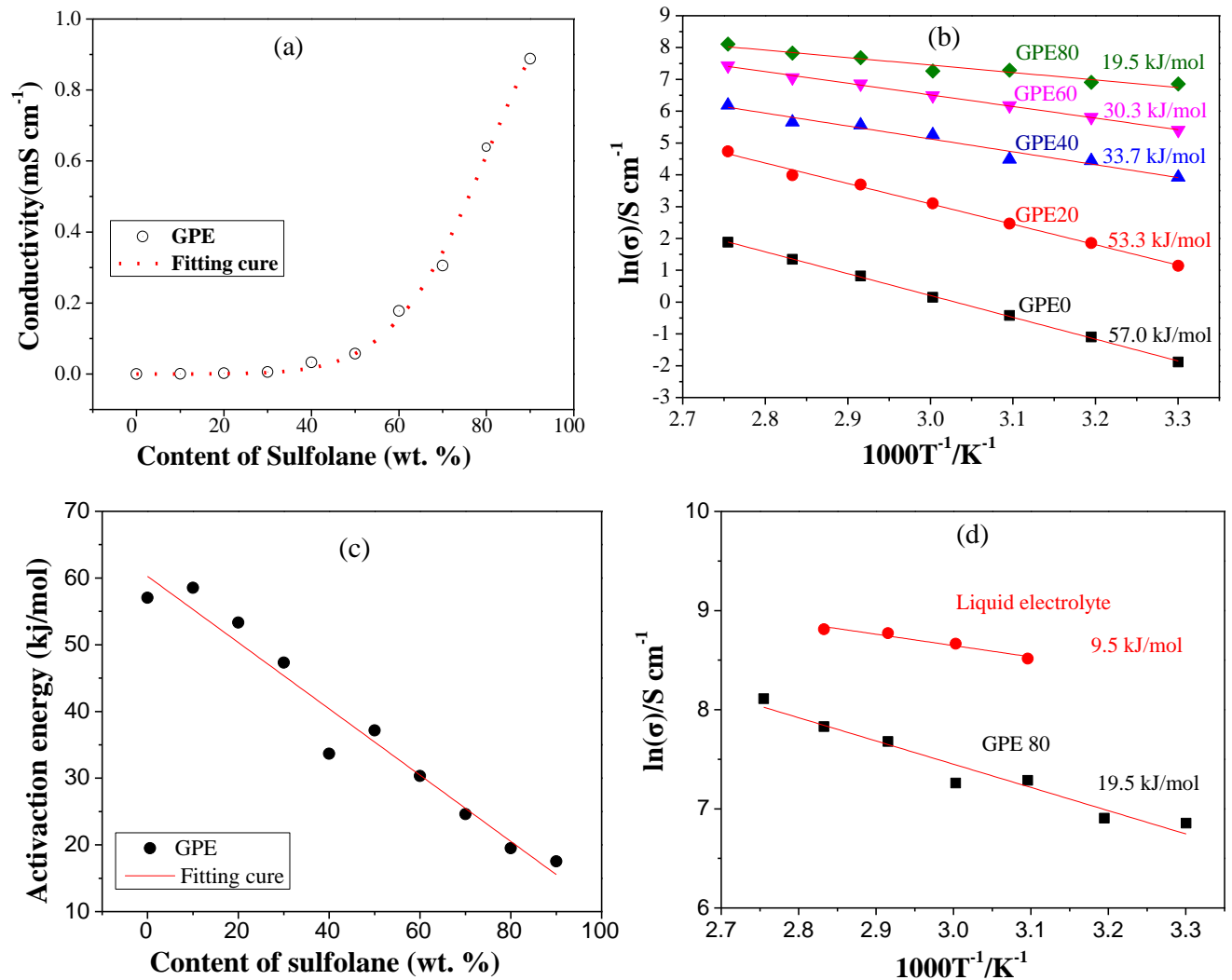

Figure 3. (a) The ionic conductivity of GPE changes with the content of sulfolane at $30^{\circ} \mathrm{C}$; (b) the relation between $\log (\sigma)$ and $1 / \mathrm{T}$ of GPE; (c) change of activation energy with sulfolane content; and (d) the relation between $\log (\sigma)$ and $1 / \mathrm{T}$ of liquid electrolyte.

The activation energy can reflect the migration difficulty of lithium ion [25]. Generally, $\sigma$ of the GPE is a Arrhenius-type relationship with the temperature $[19,24,26]$. The relationship between Log $(\sigma)$ and $1 / T$ is in accordance with the function in Equation (3) [13].

$$
\sigma=\sigma_{0} \exp \left(-\frac{E_{a}}{k T}\right)
$$


where $k$ is the Boltzmann constant, equal to $1.3806505(24) \times 10^{-23}(\mathrm{~J} / \mathrm{K})$. T is the temperature of the sample in K. $\sigma$ is the ionic conductivity of the GPE. $E_{a}$ is the activation energy; it can be computed from the slope of $\log (\sigma)=f(1 / T)$ curve obtained by linear fitting [13].

Ionic conductivity of GPEs under variable temperature were tested and results are shown in Figure S2 (Supplementary Materials). The fitting and calculation results are shown in Figure $3 \mathrm{~b}$. The results show that the activation energies of GPE-0, GPE-20, GPE-40, GPE-60, and GPE-80 are 57.0, $53.3,33.7,30.3$ and $19.5 \mathrm{~kJ} / \mathrm{mol}$, respectively. Obviously, the activation energy of GPE decreases with the increase of sulfolane. In order to further find the relationship between activation energy and the content of sulfolane, we plotted it as a scatter plot as shown in Figure 3c. Through linear fitting, it can be concluded that the activation energy is inversely proportional to the content of sulfolane. The lower activation energy indicates that the migration of $\mathrm{Li}^{+}$becomes easier. This is consistent with the change in ionic conductivity of GPE.

The activation energy of the liquid electrolyte and the comparison with CPE-80 are shown in Figure 3d. Results show that the activation energy of GPE-80 $(19.5 \mathrm{~kJ} / \mathrm{mol})$ is closer to that of conventional liquid electrolyte $(9.5 \mathrm{~kJ} / \mathrm{mol})$.

The electrochemical window test results of different GPEs are shown in Figure 4. The results show that the oxidation potentials of GPE-40, GPE-60, and GPE- 80 are 6.01, 5.96, and 5.86 V, respectively. The electrochemical window decreases slightly with increasing sulfolane content. However, they all have high electrochemical stability potential and can be used on high-voltage cathode materials.
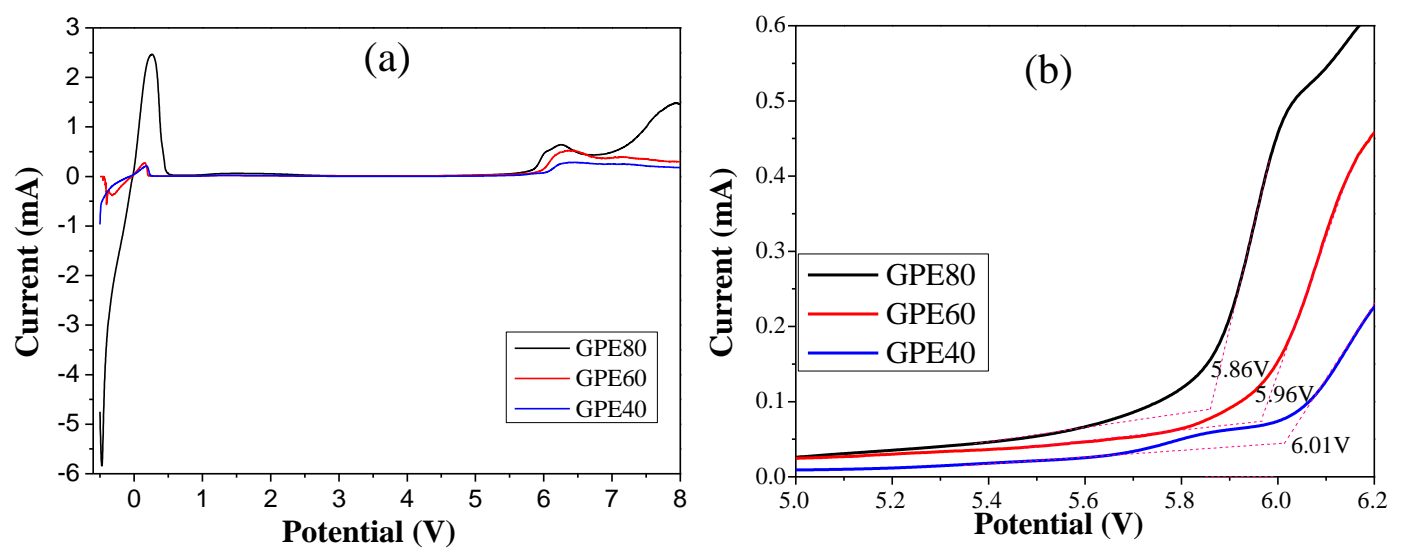

Figure 4. (a) Electrochemical window test results of GPE; (b) Enlargement of (a) at 5.0-6.2 V.

Figure $5 \mathrm{a}, \mathrm{b}$ shows the electrochemical window test results of liquid electrolyte and GPE-80. The results show that the oxidation potentials of liquid electrolyte and GPE- 80 are 4.1 and $5.8 \mathrm{~V}$, respectively. Obviously, the oxidation potential of the conventional GPE-80 is much larger than that of liquid electrolyte. Such a high oxidation potential allows it to match most existing high voltage cathode materials. 

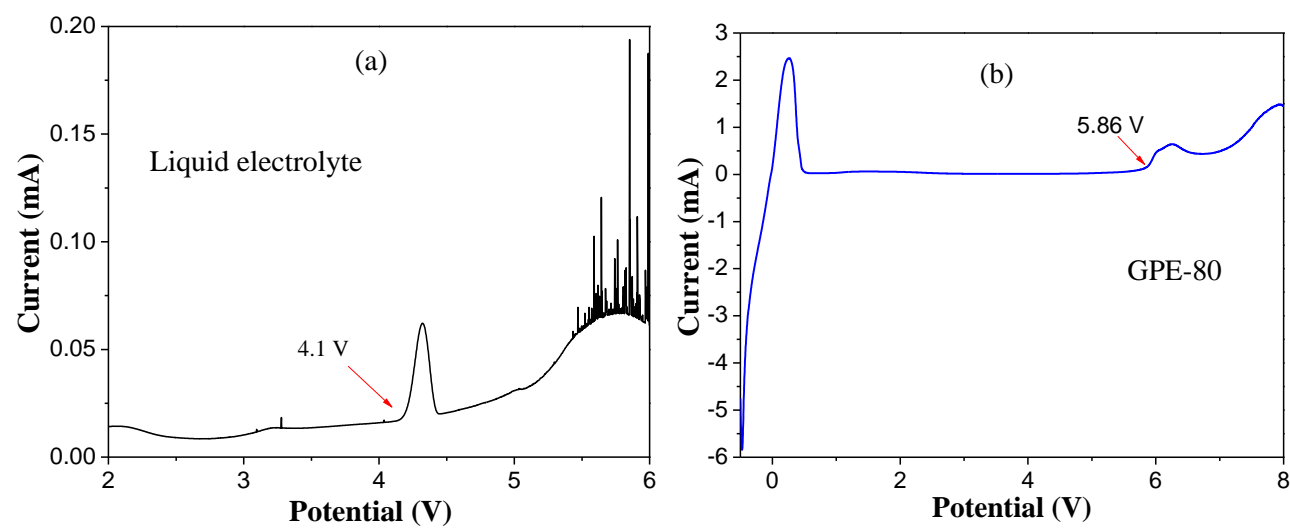

Figure 5. Electrochemical window test results of liquid electrolyte (a) and GPE-80 (b).

\subsection{Lithium Metal Battery Performance}

Taking NCM811 as the cathode material, the battery cycling performances of GPE-80 and liquid electrolyte were compared, and the results are shown in Figure 6. The changes of the specific discharge capacity of the battery under different charge and discharge cycles are shown in Figure 6a. The results show that the initial specific discharge capacities of GPE- 80 and liquid electrolyte are 176.8 and $148.3 \mathrm{mAh} / \mathrm{g}$, respectively. After 80 cycles, the discharge capacities of GPE- 80 and liquid electrolyte were 115.8 and $41.1 \mathrm{mAh} / \mathrm{g}$, and the capacity retention rates were $65.5 \%$ and $27.7 \%$, respectively. Obviously, GPE-80 has better specific discharge capacity and cycle performance than liquid electrolyte. After 140 cycles, the specific discharge capacity of GPE- 80 maintains at $96.1 \mathrm{mAh} / \mathrm{g}$, and the capacity retention rate reached $54.3 \%$.
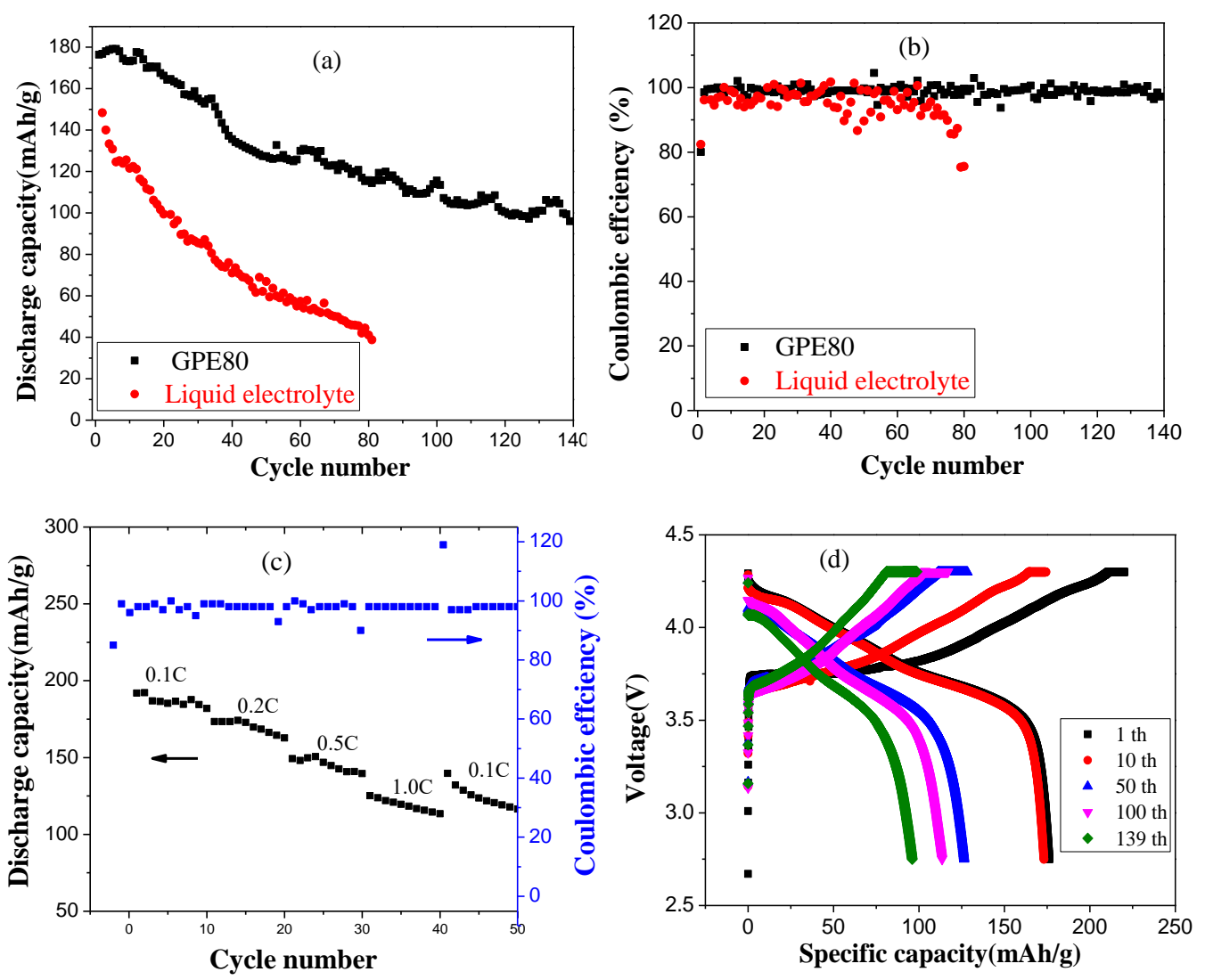

Figure 6. Characterization of lithium battery performance of GPE-80 and liquid electrolyte: (a) Cycle performance; (b) coulombic efficiency; (c) rate performance; and (d) charge and discharge profiles of GPE-80 at different cycles. 
Figure $6 \mathrm{~b}$ shows the coulombic efficiency test results of GPE- 80 and liquid electrolyte. The initial coulombic efficiency of GPE- 80 and the liquid electrolyte are $80.1 \%$ and $82.4 \%$, respectively. However, it can be seen from the results that the change in the coulombic efficiency of the liquid electrolyte is larger than that of GPE- 80 during cycling. Through 80 cycles, the coulombic efficiency of the liquid electrolyte decreased to $75.3 \%$. An apparent internal side reaction occurred. For GPE-80, the coulombic efficiency was very stable, staying at approximately $99 \%$. This stability indicates that the side reaction is minimal, and less energy is lost during charging and discharging, which is consistent with the electrochemical window test results. The electrochemical window of GPE-80 is greater than the operating voltage of NCM811 of $4.3 \mathrm{~V}$. Therefore, GPE- 80 has few side reactions and a high coulombic efficiency. In contrast, the oxidation potential of the liquid electrolyte was lower than $4.3 \mathrm{~V}$ for NCM811 as shown in Figure 5a. Therefore, during the charging and discharging process, it will continue to decompose. Therefore, its coulombic efficiency is low and changes greatly.

Figure $6 \mathrm{c}$ shows the rate performance of GPE- 80 at different discharge current densities. The results show that the discharge capacities at 0.1 C, 0.2 C, 0.5 C, and $1.0 \mathrm{C}$ are 191.9, 173.4, 149.3, 125.2, and $139.7 \mathrm{mAh} / \mathrm{g}$, respectively. Obviously, it has good charge and discharge rate performance. Figure $6 \mathrm{~d}$ shows the charge and discharge profiles of GPE- 80 at different cycles. The results show that it is a typical charge and discharge curve of NCM cathode material, and has an inclined discharge platform. The specific charge capacity and the specific discharge capacity decreased gradually with increasing number of cycles, which is consistent with the cycle test results.

To further study the effect of an electrolyte on the suppression of dendrites, we performed SEM tests on the lithium anodes, and results are shown in Figure 7. As shown in Figure 7a,e, the microstructure of the surface of fresh lithium metal is rough and uneven, and oriented in a gully-like structure. Figure $7 \mathrm{~b}, \mathrm{f}$ are SEM images of lithium negative electrodes in Li|GPE-80|Li cells after 1000 cycles. Obviously, the gully-like structure disappears, indicating that during the cycle of the battery, the lithium stripping/plating fills the original gullies. Spherical lithium can be observed on the surface. According to statistics, the minimum, maximum, and average diameters are $0.65,3.76$, and $1.84 \mu \mathrm{m}$, respectively.

Figure 7c,g are SEM images of lithium electrodes in liquid electrolytes after 80 cycles. The surface is very uneven and has large particles. The minimum, maximum, and average diameters are 10.94, 43.17, and $28.12 \mu \mathrm{m}$, respectively. Figure 7d,h shows SEM images of lithium electrodes in GPE-80 full cells after 80 cycles. The surface is relatively uniform and flat, and the diameter of the particles on the surface is small. Through statistics, the minimum, maximum, and average diameters are $0.13,0.45$, and $0.28 \mu \mathrm{m}$, respectively.

Obviously, the spherical lithium particles in the GPE80 electrolyte are much smaller than those in the liquid electrolyte. GPE80 can suppress the growth of lithium dendrites.

To study the SEI (solid electrolyte interphases) on the lithium electrode and the dissolution of ions on a positive NCM, we performed semi quantitative EDS elemental analysis, and the results are shown in Figure 8. The surface elemental analysis of the lithium-negative electrode in Li|GPE-80|Li cells after 1000 cycles is shown in Figure 8a. The results show that the contents of C, O, F, and S are 11.27, 80.85, 7.11 , and $0.77 \mathrm{wt}$. \%, respectively. Figure $8 \mathrm{c}$ shows that for the lithium electrode in the GPE- 80 full cell after 80 cycles, the C, O, F, and S contents are 38.99, 38.44, 20.54, and $2.03 \mathrm{wt}$. \%, respectively. Obviously, symmetrical cells and full cells have the same element type, but differ in composition. 

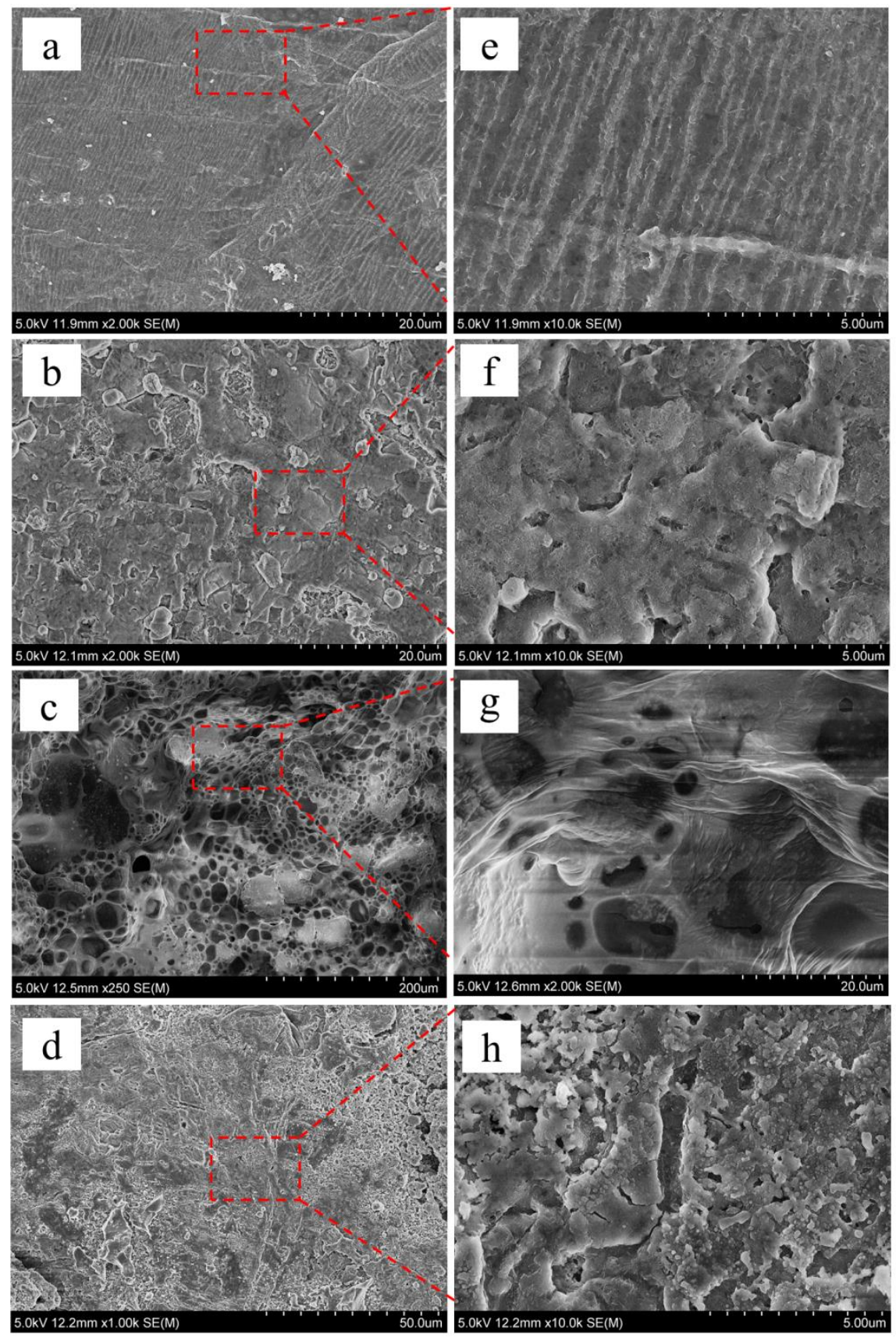

Figure 7. SEM images of lithium negative electrode: (a) Fresh lithium tablets, (b) in Li|GPE-80|Li cell after 1000 cycles, (c) in liquid electrolyte after 80 cycles, (d) and in GPE-80 full cell after 80 cycles. (e-h) are magnified images of selected areas in $(\mathbf{a}-\mathbf{d})$, respectively.

Element analysis of the lithium anode in liquid electrolyte after 80 cycles is shown in Figure $8 \mathrm{~b}$. The results show that the contents of $\mathrm{C}, \mathrm{O}, \mathrm{F}, \mathrm{Al}, \mathrm{P}$, and $\mathrm{K}$ are 21.52, 33.90, 12.47, 1.08, and $0.32 \mathrm{wt}$. \%, respectively. Comparing the elemental analysis results in Figure $8 \mathrm{~b}, \mathrm{c}$ reveals that the liquid electrolyte is seriously decomposing during cycling. The presence of $\mathrm{P}$ on the negative electrode demonstrates the lithium salt $\mathrm{LiPF}_{6}$ decomposes and is deposited as a precipitate on the surface of the lithium electrode. The presence of $\mathrm{Al}$ demonstrates the occurrence of corrosion of the $\mathrm{Al}$ foil. The presence of Ni indicates the dissolution of $\mathrm{Ni}$ from the positive electrode NCM811 material.

For GPE80, no elements such as $\mathrm{Al}, \mathrm{P}$, and $\mathrm{Ni}$ are detected on the lithium negative electrode. This further proves its high electrochemical stability, and ability to be used with high-voltage cathode materials. 

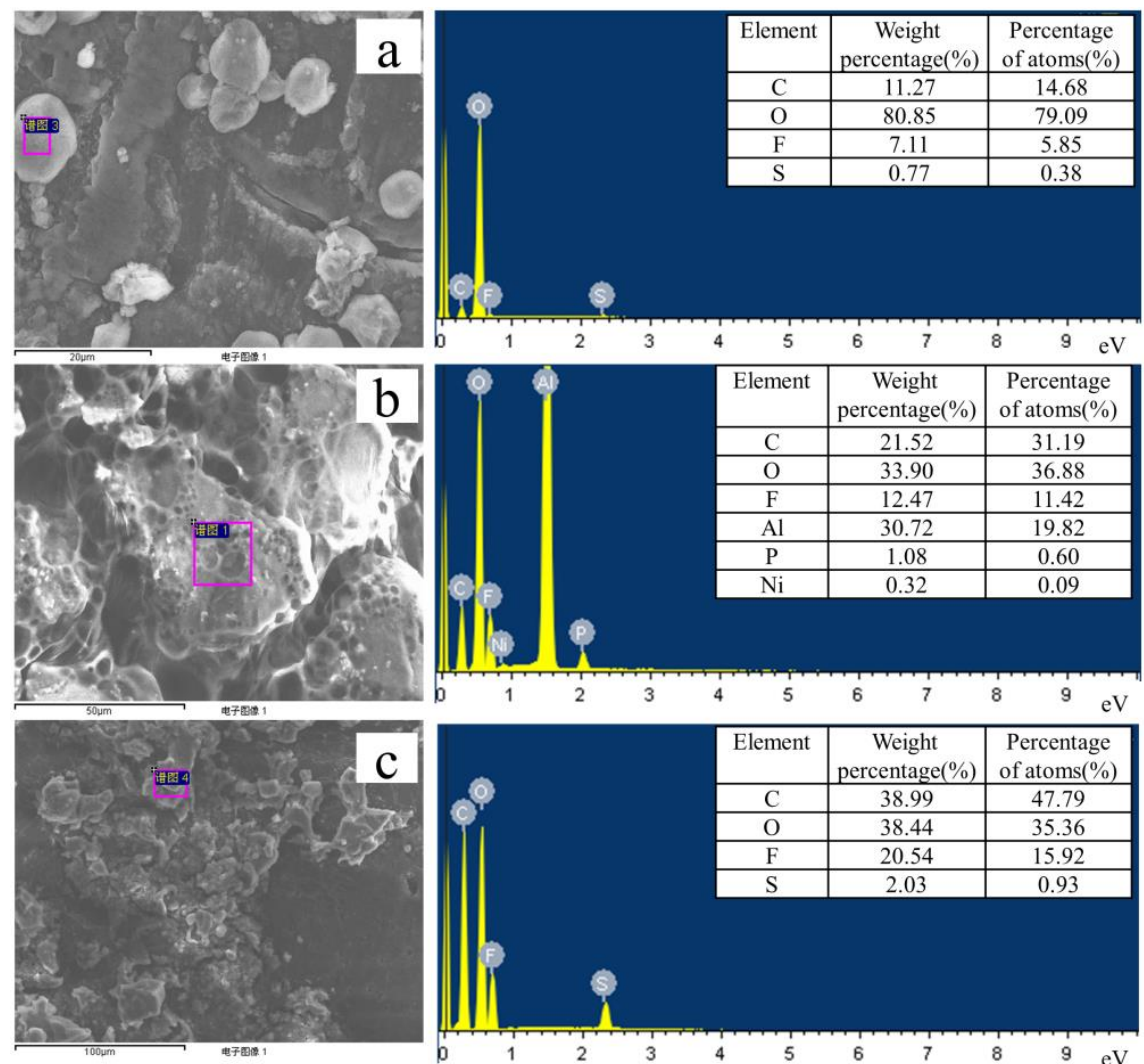

Figure 8. EDS tests results of lithium electrodes: (a) In Li|GPE-80|Li cell after 1000 cycles, (b) in liquid electrolyte after 80 cycles, and (c) in a GPE-80 full cell after 80 cycles.

\section{Conclusions}

A sulfolane plasticized gel electrolyte was prepared by in situ photocuring. The effect of the sulfolane content on the ionic conductivity of the polymer gel electrolytes was researched. Through curve fitting, we found that the ionic conductivity variation trend was in good agreement with the exponential function model. And the ionic conductivity of GPE increases faster when the sulfolane content is higher than $50 \%$. This provides inspiration for the preparation of high ionic conductivity GPE. Through curve fitting, the activation energy was inversely proportional to the sulfolane content. That indicates that the lower the activation energy is, the easier Li+ migrates. For the sulfolane content of $80 \%$ in GPE-80 (19.5 kJ/mol), the activation energy is closer to conventional liquid electrolyte $(9.5 \mathrm{~kJ} / \mathrm{mol})$. Simultaneously, its ionic conductivity and electrochemical window reached $0.64 \mathrm{mS} / \mathrm{cm}$ and $5.86 \mathrm{~V}$, respectively. The battery performance test showed that GPE- 80 has a better specific discharge capacity and cycling performance than a liquid electrolyte. After 140 cycles, the specific discharge capacity of GPE- 80 was maintained at $96.1 \mathrm{mAh} / \mathrm{g}$, and the capacity retention rate reached $54.3 \%$. SEM results indicated that GPE-80 can suppress the growth of lithium dendrites. The EDS test shows that GPE- 80 can inhibit the dissolution of metal ions in the cathode material, and is better than conventional liquid electrolyte. In summary, such a high oxidation potential allows it to match most existing high voltage cathode materials, and far exceed conventional liquid electrolytes $(4.1 \mathrm{~V})$, indicating that sulfolane-plasticized PEGDA polymer is a high-voltage gel electrolyte with excellent electrochemical stability.

Supplementary Materials: The following are available online at http://www.mdpi.com/2073-4360/11/8/1306/s1, Figure S1: (a) Nyquist plots of GPEs with different content of sulfolane at $30{ }^{\circ} \mathrm{C}$; Partial amplification of (a) with the different contents of sulfolane: (b) $20 \mathrm{wt}$. \% and $30 \mathrm{wt}$. \%, (c) $40 \mathrm{wt}$. \% and $50 \mathrm{wt}$. \%. (d) from $60 \mathrm{wt}$. to 90 wt. \%, Figure S2: Figure S2. Nyquist plots of different GPEs under variable temperature conditions: (a) GPE-0, (b) GPE-20, (c) GPE-40, (d) GPE-60, (e) GPE-80. 
Author Contributions: Conceptualization, S.W. and C.W.; Methodology, S.W.; Data calculation, S.W.; Electrochemical performance testing, W.D. and L.Z. (Linmin Zou); Writing-original draft preparation, S.W. and Y.G.; Writing-review and editing, C.W, Y.L., L.Z. (Limin Zang) and Y.G.; Funding acquisition, C.W., X.X. and S.W.

Funding: This research was supported by Guangxi Science and Technology Plan Project of China (Grant No.: AC17195028), National Natural Science Foundation of China (Grant No.: 51863006), Guangxi Natural Science Foundation of China (Grant No.: 2018GXNSFAA138131), Project of Department of Science and Technology of Guilin (Grant No.: 2016012005).

Conflicts of Interest: The authors declare no conflict of interest.

\section{References}

1. Nitta, N.; Wu, F.X.; Lee, J.T.; Yushin, G. Li-ion battery materials: Present and future. Mater. Today 2015, 18, 252-264. [CrossRef]

2. Goodenough, J.B.; Park, K.S. The li-ion rechargeable battery: A perspective. J. Am. Chem. Soc. 2013, 135, 1167-1176. [CrossRef] [PubMed]

3. Marom, R.; Amalraj, S.F.; Leifer, N.; Jacob, D.; Aurbach, D. A review of advanced and practical lithium battery materials. J. Mater. Chem. 2011, 21, 9938-9954. [CrossRef]

4. Goodenough, J.B. How we made the li-ion rechargeable battery. Nat. Electron. 2018, 1, 204. [CrossRef]

5. Kim, J.; Lee, H.; Cha, H.; Yoon, M.; Park, M.; Cho, J. Prospect and reality of ni-rich cathode for commercialization. Adv. Energy Mater. 2018, 8, 1702028. [CrossRef]

6. Lim, J.M.; Hwang, T.; Kim, D.; Park, M.S.; Cho, K.; Cho, M. Intrinsic origins of crack generation in ni-rich $\mathrm{LiNi}_{0.8} \mathrm{Co}_{0.1} \mathrm{Mn}_{0.1} \mathrm{O}_{2}$ layered oxide cathode material. Sci. Rep. 2017, 7, 39669. [CrossRef] [PubMed]

7. $\mathrm{Xu}, \mathrm{K}$. Nonaqueous liquid electrolytes for lithium-based rechargeable batteries. Chem. Rev. 2004, 104, 4303-4418. [CrossRef]

8. Manthiram, A.; Yu, X.W.; Wang, S.F. Lithium battery chemistries enabled by solid-state electrolytes. Nat. Rev. Mater. 2017, 2, 16103. [CrossRef]

9. Chen, S.; Wen, K.; Fan, J.; Bando, Y.; Golberg, D. Progress and future prospects of high-voltage and high-safety electrolytes in advanced lithium batteries: From liquid to solid electrolytes. J. Mater. Chem. A 2018, 6, 11631-11663. [CrossRef]

10. Li, B.; Wang, Y.; Yang, S.B. A material perspective of rechargeable metallic lithium anodes. Adv. Energy Mater. 2018, 8, 1702296. [CrossRef]

11. Li, S.; Jiang, M.; Xie, Y.; Xu, H.; Jia, J.; Li, J. Developing high-performance lithium metal anode in liquid electrolytes: Challenges and progress. Adv. Mater. 2018, 30, 1706375. [CrossRef]

12. Cheng, X.L.; Pan, J.; Zhao, Y.; Liao, M.; Peng, H.S. Gel polymer electrolytes for electrochemical energy storage. Adv. Energy Mater. 2018, 8, 1702184. [CrossRef]

13. Liang, S.; Yan, W.; Wu, X.; Zhang, Y.; Zhu, Y.; Wang, H.; Wu, Y. Gel polymer electrolytes for lithium ion batteries: Fabrication, characterization and performance. Solid State Ion. 2018, 318, 2-18. [CrossRef]

14. Alarco, P.J.; Abu-Lebdeh, Y.; Abouimrane, A.; Armand, M. The plastic-crystalline phase of succinonitrile as a universal matrix for solid-state ionic conductors. Nat. Mater. 2004, 3, 476-481. [CrossRef]

15. Kim, S.H.; Choi, K.H.; Cho, S.J.; Park, J.S.; Cho, K.Y.; Lee, C.K.; Lee, S.B.; Shim, J.K.; Lee, S.Y. A shape-deformable and thermally stable solid-state electrolyte based on a plastic crystal composite polymer electrolyte for flexible/safer lithium-ion batteries. J. Mater. Chem. A 2014, 2, 10854-10861. [CrossRef]

16. Liu, K.; Ding, F.; Lu, Q.; Liu, J.; Zhang, Q.; Liu, X.; Xu, Q. A novel plastic crystal composite polymer electrolyte with excellent mechanical bendability and electrochemical performance for flexible lithium-ion batteries. Solid State Ion. 2016, 289, 1-8. [CrossRef]

17. Lin, D.; Yuen, P.Y.; Liu, Y.; Liu, W.; Liu, N.; Dauskardt, R.H.; Cui, Y. A silica-aerogel-reinforced composite polymer electrolyte with high ionic conductivity and high modulus. Adv. Mater. 2018, 30, 1802661. [CrossRef]

18. Lv, P.; Li, Y.; Wu, Y.; Liu, G.; Liu, H.; Li, S.; Tang, C.; Mei, J.; Li, Y. Robust succinonitrile-based gel polymer electrolyte for lithium-ion batteries withstanding mechanical folding and high temperature. ACS Appl. Mater. Interfaces 2018, 10, 25384-25392. [CrossRef]

19. Li, S.; Chen, Y.M.; Liang, W.; Shao, Y.; Liu, K.; Nikolov, Z.; Zhu, Y. A superionic conductive, electrochemically stable dual-salt polymer electrolyte. Joule 2018, 2, 1838-1856. [CrossRef] 
20. Cui, X.; Zhang, H.; Li, S.; Zhao, Y.; Mao, L.; Zhao, W.; Li, Y.; Ye, X. Electrochemical performances of a novel high-voltage electrolyte based upon sulfolane and $\gamma$-butyrolactone. J. Power Sources 2013, 240, 476-485. [CrossRef]

21. Li, S.Y.; Zhao, Y.Y.; Shi, X.M.; Li, B.C.; Xu, X.L.; Zhao, W.; Cui, X.L. Effect of sulfolane on the performance of lithium bis(oxalato)borate-based electrolytes for advanced lithium ion batteries. Electrochim. Acta 2012, 65, 221-227. [CrossRef]

22. Sawhney, A.S.; Pathak, C.P.; Hubbell, J.A. Bioerodible hydrogels based on photopolymerized poly(ethylene glycol)-co-poly(alpha-hydroxy acid) diacrylate macromers. Macromolecules 1993, 26, 581-587. [CrossRef]

23. Tan, G.X.; Wang, Y.J.; Li, J.; Zhang, S.J. Synthesis and characterization of injectable photocrosslinking poly (ethylene glycol) diacrylate based hydrogels. Polym. Bull. 2008, 61, 91-98. [CrossRef]

24. Fan, W.; Li, N.W.; Zhang, X.; Zhao, S.; Cao, R.; Yin, Y.; Xing, Y.; Wang, J.; Guo, Y.G.; Li, C. A dual-salt gel polymer electrolyte with $3 \mathrm{~d}$ cross-linked polymer network for dendrite-free lithium metal batteries. Adv. Sci. 2018, 5, 1800559. [CrossRef]

25. Anderson, O.; Stuart, D. Calculation of activation energy of ionic conductivity in silica glasses by classical methods. J. Am. Ceram. Soc. 1954, 37, 573-580. [CrossRef]

26. Peters, A.; Korte, C.; Hesse, D.; Zakharov, N.; Janek, J. Ionic conductivity and activation energy for oxygen ion transport in superlattices-the multilayer system $\mathrm{CSZ}\left(\mathrm{ZrO}^{2+} \mathrm{CaO}\right) / \mathrm{Al}_{2} \mathrm{O}_{3}$. Solid State Ion. 2007, 178, 67-76. [CrossRef]

(C) 2019 by the authors. Licensee MDPI, Basel, Switzerland. This article is an open access article distributed under the terms and conditions of the Creative Commons Attribution (CC BY) license (http://creativecommons.org/licenses/by/4.0/). 